\title{
Empirical Analysis of the Chinese Mask Industry During the Covid-19 Epidemic
}

\author{
Ziyu Yu
}

\author{
Big Bridge Academy, Wuxi, Jiangsu, China, 214000 \\ ${ }^{*}$ Corresponding author. Email: Beyonka2003@163.com
}

\begin{abstract}
Traditionally, the mask industry in China has several characteristics, including small-scale production, low technology and low human capital investment. As a result, the Chinese mask industry has a low entrance barrier which leads to high competition among various players. However, in 2020, during the outbreak of the COVID-19 pandemic, the demand for medical masks in various countries has increased dramatically, and therefore masks in China are out of stock. Nevertheless, after the pandemic remains under control, China, the first country experiencing an urgency in supply shortage, may face the problems of over-supply. This article analyzes the market changes before and after the epidemic and the successful strategies of manufacturers, and provides solutions for overcapacity after the outbreak of the epidemic. It provides ideas for Chinese enterprises to seize the opportunity to surpass famous foreign enterprises such as $3 \mathrm{M}$ and seize the dominant position in China's mask market.
\end{abstract}

Keywords: China, COVID 19, mask production, masks export

\section{INTRODUCTION}

The deterioration of global air quality and the appearance of the COVID-19 make the medical supplies such as masks and protective clothing necessary. During the outbreak of the epidemic, the sales and prices of masks increased sharply. The popularity of mask economy provides people with opportunities. Not only the original mask manufacturers expand production, but also a large number of enterprises in other industries have joined the industry. However, with the gradual improvement of epidemic prevention and control in China, the demand for masks can be expected to continue to decline. In recent years, many enterprises, including listed companies, have invested a lot of capital to extend the cross-border mask industry chain under the support of the government or market driven. After the bubble economy, the disposal of these investments and production capacity, and relevant companies' consideration of strategies to deal with the decline in demand after the boom will became a problem.

Mass production of masks can only meet the short-term market demand. According to the market situation, Chinese enterprises should find a solution to excess capacity by exploiting new trade routes. Due to the impact of the new round of the European Championship epidemic, the global people's awareness of health protection will also be improved, and the market demand of the world will gradually increase in the future. Cao Xuejun, the deputy director of the Department of consumer goods industry of the Ministry of industry and information technology, said that China is a big producer of protective clothing and encourage domestic enterprises to actively meet foreign demand and standardize production and export according to corresponding standards.[1]

Finally, this paper is divided into three parts: before, during and after the epidemic: the first part analyzes the production of masks in China before the epidemic and the geographical distribution of mask market. At the same time, the paper explains the competition in China's mask Market and the successful strategies of famous mask manufacturers to provide decision-making ideas for new enterprises in 2020. The second part shows the impact of the epidemic on the mask economy and the changes in China's market. The third part puts forward the solution of overcapacity after the outbreak of the epidemic. By collecting the masks that meet the production standards of China and compare with the import standards of other countries, the mask manufacturers in China are encouraged to enter the international trade and export masks that meet the standards. 


\section{BEFORE THE PANDEMIC}

This section is going to talk about the production environment of the mask industry in China before the pandemic. The core raw material of making a mask is high melt finger fiber polypropylene. Before the pandemic, the domestic production capacity in China is relatively sufficient and the price is relatively stable. In 2019, the output of high melting finger fiber polypropylene in China was about 900,000 tons [2]. The disposable surgical masks that can be produced by one ton of high melt finger fiber polypropylene are about 900,000-1,000,000 tons, and the number of N95 medical protective masks that can be produced by one ton of high melt finger fiber polypropylene is about 200,000-250,000.[3]

Based on the industrial chain, there are about 21,000 enterprises involved in the production and operation of masks in China, which is the largest producer and exporter of masks in the world, accounting for about $50 \%$ of the total output of global masks[3]. In 2019, the total output value of medical masks in China was about 5.491 billion yuan [4].

According to the regional distribution of medical mask manufacturers, the top ten regions in China are Henan, Jiangxi, Jiangsu, Hubei, Guangdong, Shandong, Hebei, Zhejiang, Sichuan and Fujian. Due to the obvious advantages of raw materials in the upstream of Henan Province, the number of medical mask manufacturers in China is the largest, accounting for about $19 \%$ of the country, and the total number of approved enterprises is around 68; the total number of approved enterprises in Jiangxi Province is around 56, accounting for 16\%; there are 48 Enterprises in Jiangsu Province, accounting for 13\%; there are 45 manufacturers in Hubei Province, accounting for $12 \%$ [5].

\subsection{Industry Competition}

$3 \mathrm{M}$ is a technology company from the United States. Industry experts estimate that $3 \mathrm{M}$ occupies about $90 \%$ of the market share in the whole domestic haze mask market, taking the lead in the industry [6]. In the 1970s, 3M developed the first particulate protective mask. In 1984, 3M established China Limited Company, which took the lead in introducing personal protection products into the Chinese market. On one hand, it provides free protection training for enterprise workers and actively participates in formulating the standards required by the central government, which helps shape the company's authority in the Chinese market.

Meanwhile, the company's brand gains more and more acknowledgement by the general public as the company donated both resources and money during the SARS outbreak in 2003, the Paralympic Games in 2007 and the Wenchuan earthquake in 2008 [7]. In addition, there are four more companies recognized by the public according to the "top ten brand enterprises in the mask industry in 2015" survey released by China Report Hall and they are Lvdun, Honeywell, Youvis and Baiyuan. Only Lvdun is a local brand in China. Although foreign enterprises occupy a large number of mask market shares in China, this pandemic provides Chinese producers with opportunities to seize the momentum and to replace western companies as the dominant force in the mask industry.

\subsection{Lydun's Turnover Story}

As one of the largest mask manufacturers in China, lvdun found Achilles-heels when $3 \mathrm{M}$ had the first mover advantage and channel advantage. Due to $3 \mathrm{M}^{\prime} \mathrm{s}$ experience in making years of industrial masks, their masks actually make people feel uncomfortable for daily uses. In addition, the ugly appearance of $3 \mathrm{M}$ masks and the deep indentation people's face after removing the mask have brought certain opportunities to lvdun and showed them where to improve. In September 2012, when the public opinion of haze began to rise, Shanghai Xingnuo Kanglun Fiber Co., Ltd. (hereinafter referred to as Kanglun fiber) took the lead in announcing the development of the first Lvdun mask for effective protection of PM2.5 in China. The filtration efficiency of PM2.5 is more than $99 \%$ by Nielsen laboratory [8]. The mask is made of Kanglun antibacterial fabric, which is patented by the state. The appearance of the mask is similar to that of the ordinary mask, avoiding the exaggeration and discomfort of $3 \mathrm{M}$ mask. The huge incremental market benefited Lvdun with the growth dividend. Three months after its listing, created a sales record of 2 million.

After the outbreak of PM2.5 in Beijing, Lvdun, which is more suitable for ordinary consumers to wear in their daily life, turns popular. The perfect channel establishment provides the possibility for further development of its business. Green Shield masks are distributed in 26 provinces in China with more than 30,000 terminal channels, including more than 15000 chain pharmacies in major cities such as Beijing, Shanghai and Guangzhou, convenience stores such as 7-Eleven, and e-commerce platforms such as T-mall flagship store and JD.com.

In addition, after the acquisition of North in 2008, Honeywell, a company that now occupies a large number of mask Market in China, has started the phase of building factories in China, which includes building individual protection plants in Chuzhou, Anhui and Nantong, Jiangxi Province. In 2018, Honeywell transferred overseas factories such as Australia to Xi'an in China.

Likewise, Honeywell has also changed its product design for China. According to Tong Gengsheng, the 
general manager of Honeywell safety products in China and Southeast Asia in 2013, in order to make protective products such as masks meet the human body size and needs of Chinese people, Honeywell has established a research and development center in China. This results in the establishment of the database of individual protection needs of Chinese people, the individual model database, and research and innovation conduction.

Because of engineers' in-depth research, Honeywell eventually developed a mask in line with the Chinese market. In the introduction of a kn95 mask of the company, it says that the actual filtration rate can reach $98 \%$, which is suitable for $97 \%$ of Chinese adults, and the coverage rate and fitting rate of face shape are better [9]. In addition, the use of cotton ear strap can prevent glasses from fogging.

The success of these two enterprises depends on technological breakthrough and innovation ability. In particular, the success of Lvdun is more referential for Chinese enterprises. Lvdun finds business opportunities in the product design, the enrichment of product lines, the research and development of new products, and the expansion of product use scenarios. As a result, it brings hope for corporation-wise establishment. It is an important weapon to find problems in the market and conduct differentiated competition.

\section{DURING THE PANDEMIC}

With the outbreak of the coronavirus, the demand for mask has increased dramatically. However, as the outbreak happened around the time of the Chinese Spring Festival, the majority of the labor force left for vacation. Furthermore, due to the traffic ban among cities in China, most of them can't travel back to the manufactures. As a result, the mask production is stopped. Luckily, as the pandemic gradually remains under control, over $76 \%$ of the manufactures in 22 key provinces in China have re-opened the production lines in February [10]. In addition, from January to May, there were 70,802 newly

registered mask manufactures in China, up $126 \%$ year-on-year.

Another important raw material is the melt-blown cloth. Based on statistics, there were 7,296 newly-registered companies producing or trading melt-blown fabrics, up $227 \%$ year-on-year.

\section{AFTER THE PANDEMIC}

However, China's mask production has the potential of overcapacity after the epidemic. The per capital demand has gradually declined, and the price has begun to fall. Through the e-commerce platform, it can be found that the price of disposable protective masks has been as low as 0.31 yuan / piece, and some mask factories are selling at a loss.

Therefore, exporting abroad is one of the effective ways to solve the problem of overcapacity. On April 10, the Customs issued an announcement to strengthen the standard quality control of masks. As a measure, many manufacturers of civil masks did not obtain medical device product certificates and could not export through the customs. They could only continue to sell in the domestic market. In May this year, the number of new registrations of mask and melt-blown cloth related enterprises decreased by $70.84 \%$ and $57.6 \%$ respectively compared with the peak in April [9]. Therefore, this section collects the classification and production standards of masks in some countries, and compares the production requirements of different countries to find out the production standards that are conducive to the export of masks. Take the production of daily protective masks as an example and compare the types of masks protection functions and filtration efficiency between China and European, the United States and Japan. The requirements of at least two kinds of filtration grades for export should be met by Chinese mask companies. Related indicators of production standards are shown in Table 1 and Table 2.[11]

Table1 production standards of masks in Europe, America and Japan

\begin{tabular}{|c|c|c|c|c|c|c|c|c|c|}
\hline & \multicolumn{3}{|c|}{ USA Standards } & \multicolumn{3}{|c|}{ EU Standards } & \multicolumn{3}{|c|}{ Japan Standards } \\
\hline Masks Variety & N95 & N99 & N100 & FFP1 & FFP1 & FFP3 & DS1 & DS2 & DS3 \\
\hline Filter Efficiency & $95 \%$ & $99 \%$ & $99.97 \%$ & $80 \%$ & $94 \%$ & $97 \%$ & $95 \%$ & $99 \%$ & $99.90 \%$ \\
\hline $\begin{array}{l}\text { Protection } \\
\text { function }\end{array}$ & \multicolumn{3}{|c|}{ Non-oil suspended particles } & \multicolumn{3}{|c|}{$\begin{array}{l}\text { None and sweat oil suspended } \\
\text { particles }\end{array}$} & \multicolumn{3}{|c|}{ Respiratory protection } \\
\hline Action aging & \multicolumn{3}{|c|}{ No time limit } & \multicolumn{3}{|c|}{ No time limit } & \multicolumn{3}{|c|}{ No time limit } \\
\hline
\end{tabular}

Table 2 China Daily Protective Mask Production Specification (Zheng \& Xu)

《GBT 32610-2016 Daily Protective Mask Technical Specifications》

\begin{tabular}{|l|l|l|l|l|}
\hline Filtration efficiency level & & LEVEL 1 & LEVEL 2 & LEVEL 3 \\
\hline Filtration efficiency $(\%) \geq$ & Salt & 99 & 95 & 90 \\
\hline
\end{tabular}




\begin{tabular}{|l|l|l|l|l|}
\hline & $\begin{array}{l}\text { medium } \\
\text { Oil } \\
\text { medium }\end{array}$ & 99 & 95 & 80 \\
\hline LEVEL A & LEVEL B & LEVEL C & LEVEL D \\
\hline Protection level & 90 & 85 & 75 & 65 \\
\hline Protection effect above level A, filtering effect should be above level 2 & \\
\hline Protective effect of B, C, D, filtering effect should be more than level 3 & \\
\hline Saline media: biological particles, such as influenza virus, bacteria, etc & \\
\hline Oily medium: reduce electrostatic interactions of particles, such as pollen, dust, etc
\end{tabular}

\section{CONCLUSION}

To nut shell, the Chinese mask industry has completely changed by the pandemic. In addition, due to the mask economy caused by covid-19, this paper puts forward two problems: how to solve the problem of excess capacity loss in China's mask industry after the epidemic, and how to overcome other foreign competitors to develop China's mask industry. Firstly, the mask production standards of Japan and other big countries are classified and compared. The export standards can meet other countries, and provide another solution to the problem of overcapacity after the outbreak. Secondly, by learning from the product design of $3 \mathrm{M}$ and Honeywell, the comfort and practicability of the products can be improved, so as to win the favor of customers and gain the leading power of China's mask industry.

\section{ACKNOWLEDGMENT}

I would like to thank my thesis instructor for her timely and careful guidance and help in terms of format specification, thesis key points and overall structure, so that I can successfully complete the thesis writing work. I would also like to thank the teachers for my education. In addition, I would like to thank my classmates for their ideas in writing my thesis, so that the paper can be completed as planned. Finally, I would like to thank all the experts and teachers who review the papers in their busy schedule!

\section{REFERENCES}

[1] Li Xiaoping. Is the mask industry chain a bubble or an investment opportunity? [N] Securities times, 2020.3.6 (A05).

[2] Xinhua. China takes multi-faceted measures to moderate mask prices.2020.4.28. http://en.people.cn/n3/2020/0428/c90000-9684774. html
[3] National Medical Product Administration. Single-use medical device product content. 2020. http://app1.nmpa.gov.cn/data_nmpa/face3/base.jsp ?tableId $=166 \&$ tableName $=$ TABLE166\&title $=\%$ D2 $\% \mathrm{BB} \% \mathrm{~B} 4 \% \mathrm{CE} \% \mathrm{D} 0 \% \mathrm{D} 4 \% \mathrm{CA} \% \mathrm{~B} 9 \% \mathrm{D} 3 \% \mathrm{C} 3 \% \mathrm{D} 2$ $\% \mathrm{BD} \% \mathrm{C} 1 \% \mathrm{C} 6 \% \mathrm{C} 6 \% \mathrm{~F} 7 \% \mathrm{D} 0 \% \mathrm{~B} 5 \% \mathrm{~B} 2 \% \mathrm{FA} \% \mathrm{C} 6$ $\% \mathrm{~B} 7 \& \mathrm{bcId}=159287317145647868157579642205$ ).

[4] Zhizhu.Global Face Mask Industry Research Report, Growth Trends and Competitive Analysis 2020-2026.

https://zhuanlan.zhihu.com/p/126488290

[5] Lanzhou news. Big data decodes the production capacity of China's masks, and what's the key to easing the supply shortage? 2020.02.03 http://www.lzbs.com.cn/gnnews/2020-02/03/conten t_4576387.htm

[6] Xinhua. South China launches ultra-fast mask factory. 2020.2.25.

http://en.people.cn/n3/2020/0225/c90000-9661651. html

[7] The Fujian Provincial Development and Reform Commission responded to the impact of the epidemic on related industries. National Development and Reform Commission. 2020.4.20 https://www.ndrc.gov.cn/xwdt/dt/dfdt/202004/t202 00402_1224988.html

[8] Chen Ling. China contributes to stability of global supply chain. People's Daily, 2020,3,19 http://en.people.cn/n3/2020/0319/c90000-9669940. html

[9] Zheng Chengqiong, Daniel Xu. "COVID-19's impact on China's industries.” ChinaDaily, 2020. http://www.china.org.cn/business/covid-19-econom ic-impact/node_8018307.html

[10] Lu Ya'nan, Wang Zheng, Li Xinping. “China's mask production amid COVID-19 indicates strong manufacturing capability." People's Daily, 
2020,5,24.

http://en.people.cn/n3/2020/0524/c90000-9693651.

html

[11] Jie Pan. The Path Choice of Mask Industry Development After Epidemic.[J] International Journal of Science. Vol.7 No.4. 2020. 